\title{
Avaliação Qualitativa e Quantitativa na Deposição de Calda de PULVERIZAÇÃo EM Commelina benghalensis ${ }^{1}$
}

\author{
Qualitative and Quantitative Evaluation of Spray Deposition on Commelina benghalensis
}

\author{
RODRIGUES, A.C.P. ${ }^{2}$, FILHO, S.I.B.S. ${ }^{2}$, MARTINS, D. ${ }^{3}$, COSTA, N.V. ${ }^{4}$, ROCHA, D.C. ${ }^{5}$ e \\ SOUZA, G.S.F. ${ }^{2}$
}

\begin{abstract}
RESUMO - O objetivo deste estudo foi o de avaliar a quantidade e qualidade da deposição da calda de pulverização em plantas de Commelina benghalensis, considerando os volumes de aplicação, as pontas de pulverização e o ângulo dos bicos na barra de pulverização. Foram utilizadas cinco hastes de plantas por vaso. O delineamento experimental adotado foi o inteiramente casualizado, com 20 repetições. O experimento foi conduzido em casa de vegetação e a aplicação da calda foi efetuada após 40 dias do transplantio das hastes, quando estavam com 30 a $40 \mathrm{~cm}$ de comprimento. Os tratamentos foram constituidos por cinco pontas de pulverização (TX-VK 6, TX-VK 8, XR 11001 VS, XR 11002 VS e TJ60 11002 VS), sendo testadas com dois ângulos de aplicação $\left(0^{\circ}\right.$ e $\left.+30^{\circ}\right)$, exceto a TJ60 11002 VS, e todas com dois volumes de calda distintos $\left(100\right.$ e $\left.200 \mathrm{~L} \mathrm{ha}^{-1}\right)$. Foi utilizado como traçador o corante Azul Brilhante FDC-1 na concentração de 500 ppm, para determinar a deposição da calda de pulverização. Após a aplicação, 20 hastes no total foram imediatamente coletadas e, em seguida, lavadas em $100 \mathrm{~mL}$ de água destilada, para posterior quantificação do traçador em espectrofotômetro. Os dados foram transformados em valores de depósitos por grama de massa seca e ajustados à curva de regressão pelo modelo de Gompertz. Os resultados

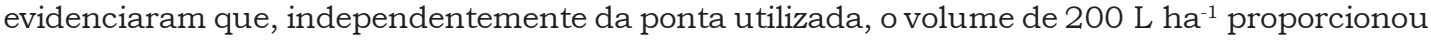
os maiores depósitos médios e pontuais nas plantas. Quanto à uniformidade do depósito de calda sobre as plantas, a ponta XR $11001 \mathrm{VS}$ no volume de $100 \mathrm{~L}^{-1}$ proporcionou a melhor uniformidade. Contudo, quando se utilizou o ângulo de $+30^{\circ}$, ocorreram acréscimos dos depósitos ao se utilizar o volume de $100 \mathrm{~L} \mathrm{ha}^{-1}$, e, nesse caso, houve melhor uniformidade para o volume de $200 \mathrm{~L} \mathrm{ha}^{-1}$.
\end{abstract}

Palavras-chave: volume de aplicação, tecnologia de aplicação, planta daninha, trapoeraba.

ABSTRACT-The objective of this study was to evaluate the quantity and quality of spray deposition on Commelina benghalensis plants, considering application volumes, spray nozzles and spray nozzle bar angle. Five stems of plants/pot were planted. The experimental treatments were arranged in a randomized design with twenty replications. The experiment was carried out under greenhouse conditions and the solution applied 40 days after the stems were transplanted, with the plants being 30 to $40 \mathrm{~cm}$ long. The treatments consisted of five spray nozzles (TX-VK 6, TX-VK 8, XR $11001 \mathrm{VS}, \mathrm{XR} 11002 \mathrm{VS}$ and TJ60 $11002 \mathrm{VS})$, tested at different application angles $\left(0^{\circ}\right.$ and $+30^{\circ}$ ) except for TJ60 $11002 \mathrm{VS}$, and two different solution volumes (100 and $\left.200 \mathrm{~L} \mathrm{ha}^{-1}\right)$. Brilliant blue FDC-1 was used as a tracer solution, at 500 ppm to determine spray deposition. After application, twenty plant stems were immediately collected, and washed in $100 \mathrm{~mL}$ of distilled water for posterior tracer quantification in a spectrophotometer. The data was fit to a regression curve using the Gompertz model. The results showed that, regardless of the type of spray nozzle used, the volume of $200 \mathrm{~L} \mathrm{ha-1}$ provided the highest deposition on the plants. The XR $11001 \mathrm{VS}$ nozzle, with volume of $100 \mathrm{~L} \mathrm{ha}^{-1}$ provided the best uniformity deposition. However, when using the angle of $+30^{\circ}$, deposition increases occurred when the volume of $100 \mathrm{~L} \mathrm{ha} \mathrm{h}^{-1}$ was used, with best uniformity being obtained with volume of $200 \mathrm{~L} \mathrm{ha}^{-1}$.

Keywords: application volume, application technology, weed, Commelina spp.

1 Recebido para publicação em 71.2.2009 e na forma revisada em 15.6.2010.

2 Doutorando em Agronomia, Dep. de Produção Vegetal da Faculdade de Ciências Agrárias - FCA/UNESP, Botucatu-SP, <andreiacpr@hotmail.com>; ${ }^{3}$ Professor Adjunto, FCA/UNESP, Fazenda Lageado, Caixa Postal 237, 18603-970 Botucatu-SP;

${ }^{4}$ Professor Adjunto, UNIOESTE/CCA, Marechal Cândido Rondon-PR; ${ }^{5}$ Professor Adjunto, Dep. de Biologia Geral, Universidade Estadual de Ponta Grossa, Ponta Grossa-PR. 


\section{INTRODUÇÃO}

A espécie Commelina benghalensis é uma das plantas daninhas mais importantes e das mais citadas na literatura brasileira, causando prejuízos econômicos às diversas lavouras. A aplicação de herbicidas para controlar as diferentes espécies de trapoeraba pode não inibir o seu desenvolvimento ou inibi-lo parcialmente, o que poderá significar prejuízos ao agricultor, como elevação dos custos e redução da produção.

A dificuldade de controle dessas espécies pode estar associada a fatores referentes à morfoanatomia dessas plantas. Costa et al. (2005) relataram que a diversidade morfológica da superficie foliar existente entre as espécies de plantas e a presença de estruturas foliares, como tricomas, estômatos, cutícula e ceras, podem exercer grande influência na aderência e deposição das gotas de pulverização, assim como na absorção do herbicida. Pesquisadores brasileiros comprovaram que as espécies de trapoeraba apresentam comportamento diferente quando são expostas ao mesmo tratamento com herbicida (Rocha et al., 2007). Por isso, recomenda-se que, antes de escolher um produto a ser aplicado para o controle de trapoerabas, seja feito o reconhecimento das espécies que estão infestando as áreas, observando as principais características que as diferenciam entre si.

Outros fatores devem ser levados em consideração para a eficácia do controle químico das plantas, como o tamanho delas, a densidade, o tamanho das gotas, a deriva, o volume de calda de pulverização, a forma da planta, a velocidade do equipamento pulverizador, as pontas e os ângulos de aplicação. Souza et al. (2007), avaliando depósitos pontuais em plantas de $C$. benghalensis amostradas individualmente, observaram que as plantas de maior área foliar foram as que receberam os menores depósitos.

A deposição e a uniformidade das aplicações de herbicidas estão diretamente relacionadas com as características tanto das folhas quanto da forma das plantas (Holloway, 1970); assim, estudos de tecnologias de aplicação tornam-se importantes para melhorar a chegada dos depósitos ao alvo.
Têm-se observado em campo inúmeras falhas no controle químico da trapoeraba, as quais podem estar relacionadas a erros na aplicação dos herbicidas. A calda pulverizada pode não estar atingindo as plantas de forma adequada, com uma boa deposição das gotas sobre suas folhas. Assim, o objetivo deste estudo foi o de avaliar a quantidade e qualidade da deposição da calda de pulverização em Commelina benghalensis, considerando volumes de aplicação, pontas de pulverização e ângulo dos bicos na barra de pulverização.

\section{MATERIAL E MÉTODOS}

O estudo foi conduzido em casa de vegetação na FCA/UNESP, campus de Botucatu-SP, no período de dezembro de 2006 a janeiro de 2007.

As plantas de Commelina benghalensis foram cultivadas em vasos com capacidade de cinco litros, contendo solo classificado como Latossolo Vermelho-Escuro, textura média, adubado conforme análise química. Utilizaram-se estacas de trapoeraba com aproximadamente $15 \mathrm{~cm}$, colocando-se cinco hastes por vaso.

Os tratamentos foram constituídos por cinco pontas de pulverização (TX-VK 6, TXVK 8, XR 11001VS, XR 11002VS e TJ 60 VS), sendo quatro delas testadas com dois ângulos de aplicação $\left(0^{\circ} \mathrm{e}+30^{\circ}\right)$, exceto a TJ 60, e todas com dois volumes de calda distintos $\left(100 \mathrm{~L} \mathrm{ha}^{-1}\right.$ e $200 \mathrm{ha}^{-1}$. A pressão de trabalho foi de $200 \mathrm{kPa}$ para as pontas XR 11001 VS e TJ60 VS no volume de $100 \mathrm{~L} \mathrm{ha}^{-1}$ e XR 11002 no volume de $200 \mathrm{ha}^{-1} ; 500 \mathrm{kPa}$ para as pontas TX-6 VS e TX-8 nos volumes de 100 e $200 \mathrm{~L} \mathrm{ha}^{-1}$, respectivamente; e $250 \mathrm{kPa}$ para a ponta TJ60 VS no volume de $200 \mathrm{~L} \mathrm{ha}^{-1}$.

Utilizou-se o delineamento inteiramente casualizado com 20 repetições. Cada haste de trapoeraba dos vasos foi considerada uma repetição, para as análises quantitativas e qualitativas, o que representou um total de 20 repetições.

A calda de pulverização foi preparada adicionando-se 0,5 g de corante Azul Brilhante (FDC-1) por litro de água destilada, o que equivale à concentração de 500 ppm, para determinar a deposição da calda de pulverização. Segundo Palladini (2005), esse corante não 
altera as características físicas da calda, podendo ser utilizado como traçador para simulação de aplicações de herbicidas.

A aplicação foi realizada aos 40 dias após o transplantio, quando as hastes das plantas se encontravam com 30 a $40 \mathrm{~cm}$ de comprimento, por meio de pulverizador estacionário pressurizado a ar comprimido com pressão constante, em sala fechada, equipado com barra de pulverização posicionada a $0,5 \mathrm{~m}$ de altura das plantas, munida de quatro pontas de pulverização, com espaçamento de $0,5 \mathrm{~m}$ entre bicos. A barra de pulverização foi deslocada à velocidade de $1 \mathrm{~m} \mathrm{~s}^{-1}$, proporcionando o consumo de calda desejado, 100 e $200 \mathrm{~L} \mathrm{ha}^{-1}$. Durante a aplicação, as condições do ambiente foram mensuradas: a temperatura e a umidade relativa do ar variaram de 28,1 a $30,7{ }^{\circ} \mathrm{C}$ e de 39 a $53 \%$, respectivamente.

Imediatamente após a aplicação da calda de pulverização, procedeu-se à coleta das hastes das plantas, que, em seguida, foram levadas ao laboratório para serem lavadas em $100 \mathrm{~mL}$ de água destilada. Para quantificar a solução do corante Azul Brilhante após lavagem das folhas e caules, determinou-se a densidade óptica (absorbância $=630 \mathrm{~nm}$ ) das soluções, utilizando-se um espectrofotômetro de UV visivel GBC, modelo Cintra 20.

Após a lavagem, as hastes foram colocadas em sacos de papel etiquetados e levadas a uma estufa de ventilação forçada de ar para secagem. Após 72 horas, quando as plantas atingiram peso constante, a uma temperatura de $60 \pm 2{ }^{\circ} \mathrm{C}$, as hastes foram retiradas e pesadas para a determinação da massa seca.

Os dados obtidos dos depósitos, em porcentagem, foram ajustados pelo modelo de Gompertz $\left(\mathrm{F}=\mathrm{e}^{\wedge}\left(\mathrm{a}-\mathrm{e}^{\wedge}\left(-\mathrm{b}-\mathrm{c}^{*} \mathrm{X}\right)\right)\right)$, para representar a frequência acumulada $(\mathrm{F})$ da deposição da calda pulverizada, em porcentagem. Adotouse o valor de 4,60517 para o parâmetro "a" do modelo, o qual representa a assintota máxima da curva, em que "e $\mathrm{e}^{\mathrm{a}}=100$, conforme o modelo ajustado por Velini (1995). O deslocamento da curva ao longo do eixo x é representado pelo módulo do parâmetro "a", e a inclinação ou concavidade da curva em relação à frequência acumulada, pelo parâmetro "c". Além disso, para melhor visualização, optou-se por apresentar as frequências não acumuladas
$\left(F N=c^{*} e^{\wedge}\left(a-b-c^{*} X-e^{\wedge}\left(-b-c^{*} X\right)\right)\right)$, que correspondem à derivada primeira do modelo. $O$ modelo de Gompertz proporciona melhor visualização das informações obtidas, uma vez que a derivada primeira do modelo permite determinar a moda da deposição da solução pulverizada nos alvos específicos, que corresponde à dose pontual mais frequente que atingiu o alvo, sendo mais preciso que a comparação por média da deposição.

Com o mesmo modelo, foram calculados os valores de média, moda, mediana e os percentis 1,5 e 10 . Os percentis foram calculados igualando-se a expressão de frequência acumulada a cada um desses valores, estimando a quantidade que recebe essa proporção de menor deposição da população de plantas avaliadas. A precisão do ajuste dos dados do modelo de Gompertz foi avaliada por meio dos coeficientes de determinação $\left(R^{2}\right)$ e pela soma dos quadrados dos resíduos das equações.

Os resultados encontrados também foram submetidos à análise de variância pelo teste $\mathrm{F}$, e as médias, comparadas pelo teste de Tukey a $5 \%$ de probabilidade. A análise de variância e a comparação de médias foram feitas pelo programa SISVAR.

\section{RESULTADOS E DISCUSSÃO}

Na Tabela 1 estão apresentados os valores médios dos depósitos que alcançaram as plantas de $C$. benghalensis. Observa-se que as pontas TX-8 VK e XR 11002 VS, independentemente do ângulo de aplicação, e a ponta TJ60 11002 VS, todas no volume de $200 \mathrm{~L} \mathrm{ha}^{-1}$, foram as que apresentaram os maiores depósitos médios de calda de pulverização entre as pontas avaliadas. Quanto ao volume utilizado, nota-se que o de $200 \mathrm{~L} \mathrm{ha}^{-1}$ foi o que se destacou, proporcionando os maiores valores de depósitos. Resultados semelhantes foram encontrados também por Scramim et al. (2002) quando avaliaram diferentes pontas de pulverização (TX-VS 8, TX-VS 4 e TJ60 8002), com relação à deposição da calda de pulverização na cultura do algodão.

Os depósitos obtidos pelas pontas TX-VK 8 e XR $11002 \mathrm{VS}$, que produzem espectro de gotas finas $(90-200 \mu)$, independentemente do ângulo de aplicação utilizado, apresentaram o mesmo efeito das gotas muito finas produzidas 
$(<90 \mu)$ pela ponta TJ60 $11002 \mathrm{VS}$; para proporcionar o volume desejado de $200 \mathrm{~L} \mathrm{ha}^{-1}$, foi utilizada uma pressão de $250 \mathrm{kPa}$. Esses resultados confirmam as considerações de Salyani (1988) e Steden (1992), de que, não necessariamente, uma gota menor propicia melhor cobertura do alvo.

Tabela 1 - Volume médio de calda depositada em plantas de Commelina benghalensis, em função dos diferentes tratamentos

\begin{tabular}{|l|c|c|c|}
\hline $\begin{array}{c}\text { Ponta de } \\
\text { Pulverização }\end{array}$ & $\begin{array}{c}\text { Volume de } \\
\text { Aplicação } \\
\left(\mathrm{L} \mathrm{ha}^{-1}\right)\end{array}$ & $\begin{array}{c}\text { Ângulo de } \\
\text { Aplicação }\end{array}$ & $\begin{array}{c}\text { Deposição } \\
\left(\mu \mathrm{L} \mathrm{g}^{-1} \mathrm{de}\right. \\
\text { massa seca) }\end{array}$ \\
\hline TX-VK 6 & 100 & $0^{\circ}$ & $159,759 \mathrm{Cd}$ \\
\hline TX-VK 6 & 100 & $+30^{\circ}$ & $196,036 \mathrm{Bc}$ \\
\hline TX-VK 8 & 200 & $0^{\circ}$ & $246,196 \mathrm{Ab}$ \\
\hline TX-VK 8 & 200 & $+30^{\circ}$ & $238,304 \mathrm{Ab}$ \\
\hline XR 11001 VS & 100 & $0^{\circ}$ & $117,502 \mathrm{D}$ \\
\hline XR 11001 VS & 100 & $+30^{\circ}$ & $116,140 \mathrm{D}$ \\
\hline XR 11002 VS & 200 & $0^{\circ}$ & $251,836 \mathrm{Ab}$ \\
\hline XR 11002 VS & 200 & $+30^{\circ}$ & $238,253 \mathrm{Ab}$ \\
\hline TJ60 11002 VS & 100 & -- & $189,653 \mathrm{bcd}$ \\
\hline TJ60 11002 VS & 200 & -- & $273,722 \mathrm{~A}$ \\
\hline F tratamento & \multicolumn{5}{|l|}{} \\
\hline d.m.s. & $11,42^{* *}$ \\
\hline CV $(\%)$ & 75,68 \\
\hline
\end{tabular}

Médias seguidas de mesma letra minúscula, na coluna, não diferem estatisticamente entre si pelo teste de Tukey $(\mathrm{p}>0,05)$. ** significativo a $1 \%$ de probabilidade.
Os menores valores de depósitos médios foram verificados para a ponta XR $11001 \mathrm{VS}$ em volume de $100 \mathrm{~L} \mathrm{ha}^{-1}$, independentemente do ângulo avaliado, sendo $215 \%$ menores em média que o maior depósito médio registrado (ponta XR 11002 VS). A mudança do ângulo de aplicação numa mesma ponta não interferiu na deposição média das gotas pulverizadas, mostrando não haver diferenças entre os ângulos de aplicação quanto à deposição (Tabela 1).

Os dados originais dos depósitos de calda de pulverização, em $\mu \mathrm{L}$ de calda $\mathrm{g}^{-1}$ de massa seca de plantas, foram analisados através de regressões, sendo os valores ajustados pelo modelo de Gompertz, bem como a média, mediana, moda e coeficiente de variação. Os coeficientes de determinação (Tabela 2) foram elevados $\left(R^{2}\right.$ entre 0,96 e 0,99$)$ para todas as pontas de pulverização, volumes e ângulos de aplicação. Assim, os valores da soma de quadrados do resíduo (desvios da regressão) apresentaram-se baixos, indicando elevada precisão dos ajustes efetuados pelo uso do modelo de Gompertz.

Utilizando a moda como parâmetro de comparação para os depósitos, observa-se nas plantas amostradas que, independentemente da ponta utilizada, o volume de $200 \mathrm{~L} \mathrm{ha}^{-1}$

Tabela 2 - Resultados das análises de regressão das frequências acumuladas e valores de média, mediana, moda e coeficiente de variação dos depósitos do traçador, em $\mu \mathrm{L}$ de calda $\mathrm{g}^{-1}$ de massa seca, em plantas de Commelina benghalensis para diferentes tratamentos

\begin{tabular}{|c|c|c|c|c|c|c|c|c|c|c|c|}
\hline \multirow{3}{*}{ Modelo } & & \multicolumn{2}{|c|}{ TX-VK 6} & \multicolumn{2}{|c|}{ TX-VK 8} & \multicolumn{2}{|c|}{ XR $11001 \mathrm{VS}$} & \multicolumn{2}{|c|}{ XR 11002 VS } & \multicolumn{2}{|c|}{ TJ60 11002 VS } \\
\hline & & \multicolumn{10}{|c|}{ Ângulo } \\
\hline & & $0^{\circ}$ & $+30^{\circ}$ & $0^{\circ}$ & $+30^{\circ}$ & $0^{\circ}$ & $+30^{\circ}$ & $0^{\circ}$ & $+30^{\circ}$ & -- & -- \\
\hline \multirow{2}{*}{$\mathrm{y}=\mathrm{e}^{\wedge}\left[\mathrm{a}-\mathrm{e}^{\wedge}\left(-\mathrm{b}-\mathrm{c}^{*} \mathrm{x}\right)\right]$} & & \multicolumn{10}{|c|}{ Volume $\left(\mathrm{L} \mathrm{ha}^{-1}\right)$} \\
\hline & & 100 & 100 & 200 & 200 & 100 & 100 & 200 & 200 & 100 & 200 \\
\hline \multirow{3}{*}{$\begin{array}{l}\text { Estimativa dos } \\
\text { parâmetros }\end{array}$} & $\mathrm{a}$ & 4,605 & 4,605 & 4,605 & 4,605 & 4,605 & 4,605 & 4,605 & 4,605 & 4,605 & 4,605 \\
\hline & $\mathrm{b}$ & $-3,333$ & $-2,937$ & $-2,821$ & $-3,201$ & $-3,343$ & $-2,884$ & $-2,434$ & $-2,932$ & $-2,345$ & $-2,548$ \\
\hline & $\mathrm{c}$ & 0,025 & 0,019 & 0,013 & 0,016 & 0,035 & 0,029 & 0,012 & 0,016 & 0,013 & 0,011 \\
\hline SQRegressão & & 677,74 & 636,06 & 655,53 & 683,84 & 644,40 & 692,31 & 646,88 & 628,92 & 659,77 & 681,09 \\
\hline SQResíduo & & 4,61 & 14,89 & 19,86 & 23,51 & 7,61 & 17,91 & 8,73 & 15,63 & 25,32 & 4,12 \\
\hline SQTotal & & 682,36 & 650,95 & 675,39 & 707,35 & 652,01 & 710,22 & 655,60 & 644,55 & 685,09 & 685,21 \\
\hline FRegressão & & $4,83 * *$ & $227,73 * *$ & $176,08^{* *}$ & $155,17 * *$ & $452,21 * *$ & $206,23 * *$ & $395,64 * *$ & $214,58 * *$ & $138,93 * *$ & $879,95 * *$ \\
\hline $\mathrm{R}^{2}$ & & 0,98 & 0,99 & 0,97 & 0,97 & 0,97 & 0,99 & 0,98 & 0,99 & 0,96 & 0,99 \\
\hline Média & & 159,76 & 196,04 & 246,20 & 238,30 & 117,50 & 116,14 & 251,84 & 238,25 & 189,65 & 273,72 \\
\hline Mediana & & 148,57 & 178,57 & 252,98 & 224,37 & 105,38 & 110,94 & 259,31 & 211,44 & 205,42 & 277,57 \\
\hline Moda & & 133,86 & 158,76 & 223,89 & 201,32 & 94,97 & 98,43 & 225,37 & 187,95 & 177,65 & 242,67 \\
\hline $\mathrm{CV}(\%)$ & & 0,34 & 0,49 & 0,45 & 0,51 & 0,59 & 0,91 & 0,29 & 0,41 & 0,66 & 0,19 \\
\hline
\end{tabular}

$\mathrm{X}=$ porcentagem de depósito do traçador em relação ao total aplicado; A, B e C são estimativas dos parâmetros do modelo para o traçador ** - significativo a $1 \%$ de probabilidade. 
proporcionou os maiores valores de moda, o que determina valores pontuais de depósitos mais frequentes nas plantas de $C$. benghalensis, quando comparado com o volume de $100 \mathrm{~L} \mathrm{ha}^{-1}$ (Tabela 2).

Assim, o aumento no volume aplicado proporcionou incremento no volume de depósitos pontuais encontrados nas plantas. Analisando os tratamentos em que foi aplicado um volume de $200 \mathrm{~L} \mathrm{ha}^{-1}$, observa-se que o maior valor de depósitos pontuais foi conferido à ponta TJ60 $11002 \mathrm{VS}$, seguida pelas pontas XR 11002 VS e TX-VK 8, ambas com ângulo de aplicação de $0^{\circ}$, sendo estes depósitos pontuais superiores na ordem de 7,68 e 8,39\%, respectivamente (Tabela 2). Para o volume de $100 \mathrm{~L} \mathrm{ha}^{-1}$, verifica-se que a ponta TJ60 11002 VS também foi a que proporcionou os maiores valores de depósitos pontuais.

Com a utilização do ângulo de $+30^{\circ}$ nas pontas de pulverização, ocorreram incrementos nos depósitos pontuais para o volume de $100 \mathrm{~L} \mathrm{ha}^{-1}$; já para o volume de $200 \mathrm{~L} \mathrm{ha}^{-1}$ ocorreu o inverso: os valores de depósitos pontuais mais frequentes da calda de pulverizada foram reduzidos (Tabela 2). Provavelmente, a maior angulação pode ter favorecido a ocorrência de deriva, uma vez que pulverizações com maior volume de aplicação favorecem a formação de gotas com diâmetros reduzidos.

Dessa forma, pode-se inferir que, em condições de campo, aplicações de volumes reduzidos de calda com angulação na ponta de pulverização podem proporcionar resultados mais eficientes das aplicações de produtos fitossanitários.

Nas Figuras 1 e 2 estão apresentadas as curvas de frequência acumulada e não acumulada, respectivamente, para os depósitos de calda de pulverização em plantas de C. benghalensis, promovidos por diferentes pontas de pulverização e volumes de aplicação. Curvas menos inclinadas significam maior dispersão dos dados, o que resulta em maiores variações nos depósitos unitários.

A frequência não acumulada, ou densidade de probabilidade, corresponde à derivada primeira da curva de frequência acumulada. Os picos presentes nas curvas representam a curtose, que mostra a frequência de valores extremos. Isso pode ser entendido da seguinte maneira: quanto mais plano é o pico da curva, maior a quantidade desses valores e, consequentemente, mais desuniformes eles se apresentam (Velini, 1995).

Utilizando o parâmetro "c" do modelo de Gompertz (Tabela 2), em que os maiores valores indicam menores inclinações das curvas e maior uniformidade de deposição da calda de pulverização, e analisando as Figuras 1 e 2 , verifica-se que os tratamentos que produziram os depósitos de calda mais uniformes foram os correspondentes à ponta XR $11001 \mathrm{VS}$ no volume de $100 \mathrm{~L} \mathrm{ha}^{-1}$ nos dois ângulos de aplicação testados, sendo estes os tratamentos que mostraram os menores valores pontuais de deposição.

Nesta avaliação, o tratamento que conferiu o menor valor para o parâmetro "c" (menor inclinação da curva), mostrando maior desuniformidade das gotas pulverizadas, foi o correspondente à ponta TJ 6011002 VS no volume de $200 \mathrm{~L} \mathrm{ha}^{-1}$. Ressalta-se que essa ponta proporcionou o maior valor de depósitos pontuais, ou seja, maior valor de moda, e o maior valor médio dos depósitos (Tabelas 1 e 2) entre os tratamentos testados no volume de $200 \mathrm{~L} \mathrm{ha}^{-1}$.

Para a ponta TJ 6011002 VS proporcionar o volume desejado de $200 \mathrm{~L} \mathrm{ha}^{-1}$, foi utilizada uma pressão de $250 \mathrm{kPa}$ o que lhe conferiu um espectro de gotas muito finas, com menor diâmetro mediano volumétrico (DMV), que foi menos eficiente do que as pulverizações realizadas com gotas. Isso pode ser explicado pela quantidade de movimento adquirido pelas gotas (momento linear), em função da velocidade e da massa da gota, que leva uma gota de massa maior a uma distância também maior. Essa massa maior faz com que a gota sofra menor influência de outras forças, como, por exemplo, a resistência do ar e a turbulência causada pelo movimento do ar devido ao deslocamento das gotas do jato de pulverização; além disso, as gotas menores apresentariam menor tempo de duração, em função da evaporação.

Verificou-se maior desuniformidade nos depósitos da calda de pulverização quando se utilizou a angulação $+30^{\circ}$ no volume de $100 \mathrm{~L} \mathrm{ha}^{-1}$, em relação ao volume de $200 \mathrm{~L} \mathrm{ha}^{-1}$. Dessa forma, a produção do maior número de gotas no volume de $200 \mathrm{~L} \mathrm{ha}{ }^{1}$ pode explicar a maior uniformidade dos depósitos. 


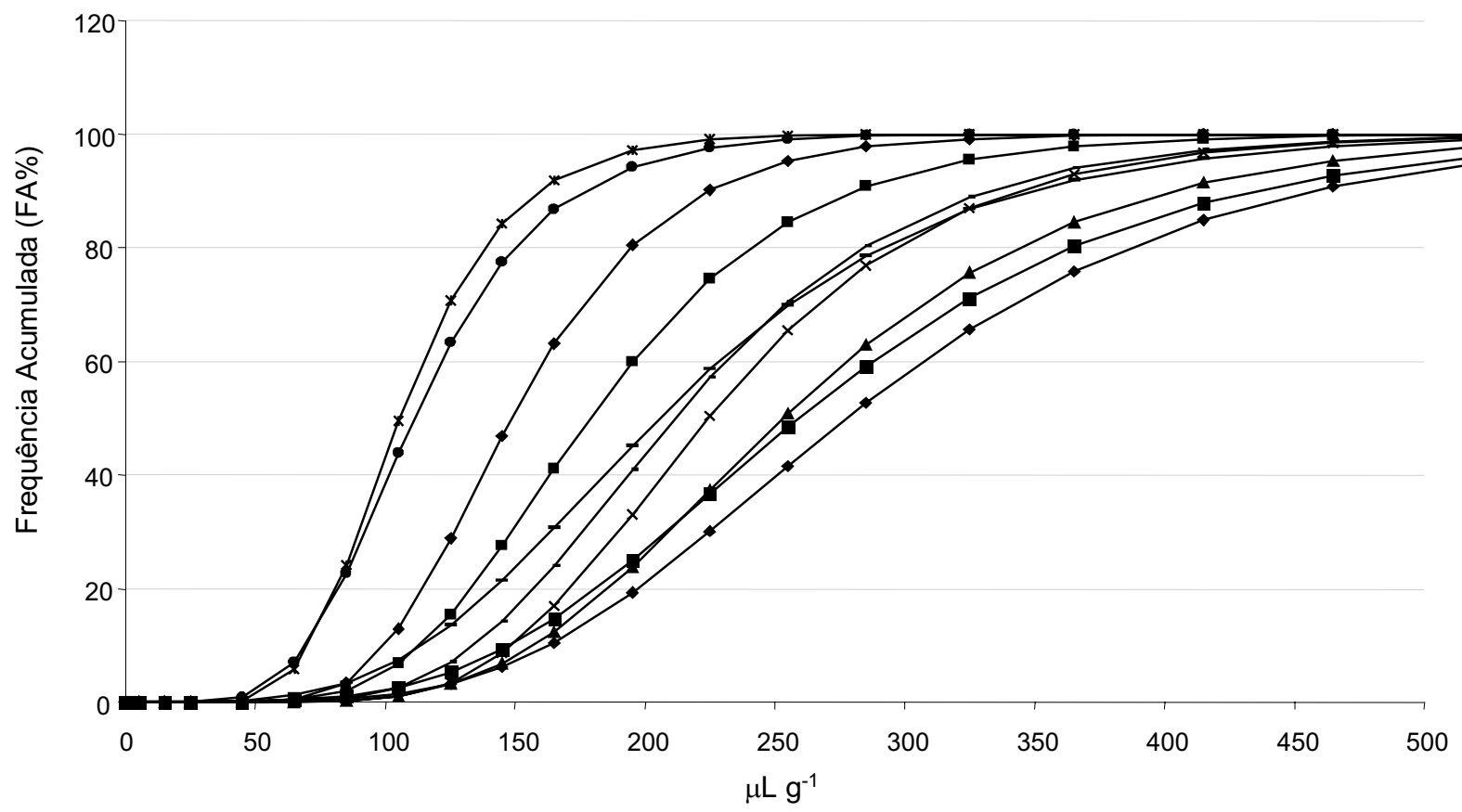

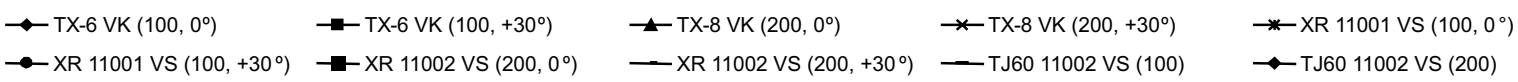

Figura 1 - Frequências acumuladas em função da deposição do traçador em plantas de Commelina benghalensis, para diferentes volumes, ângulos e pontas de pulverização.

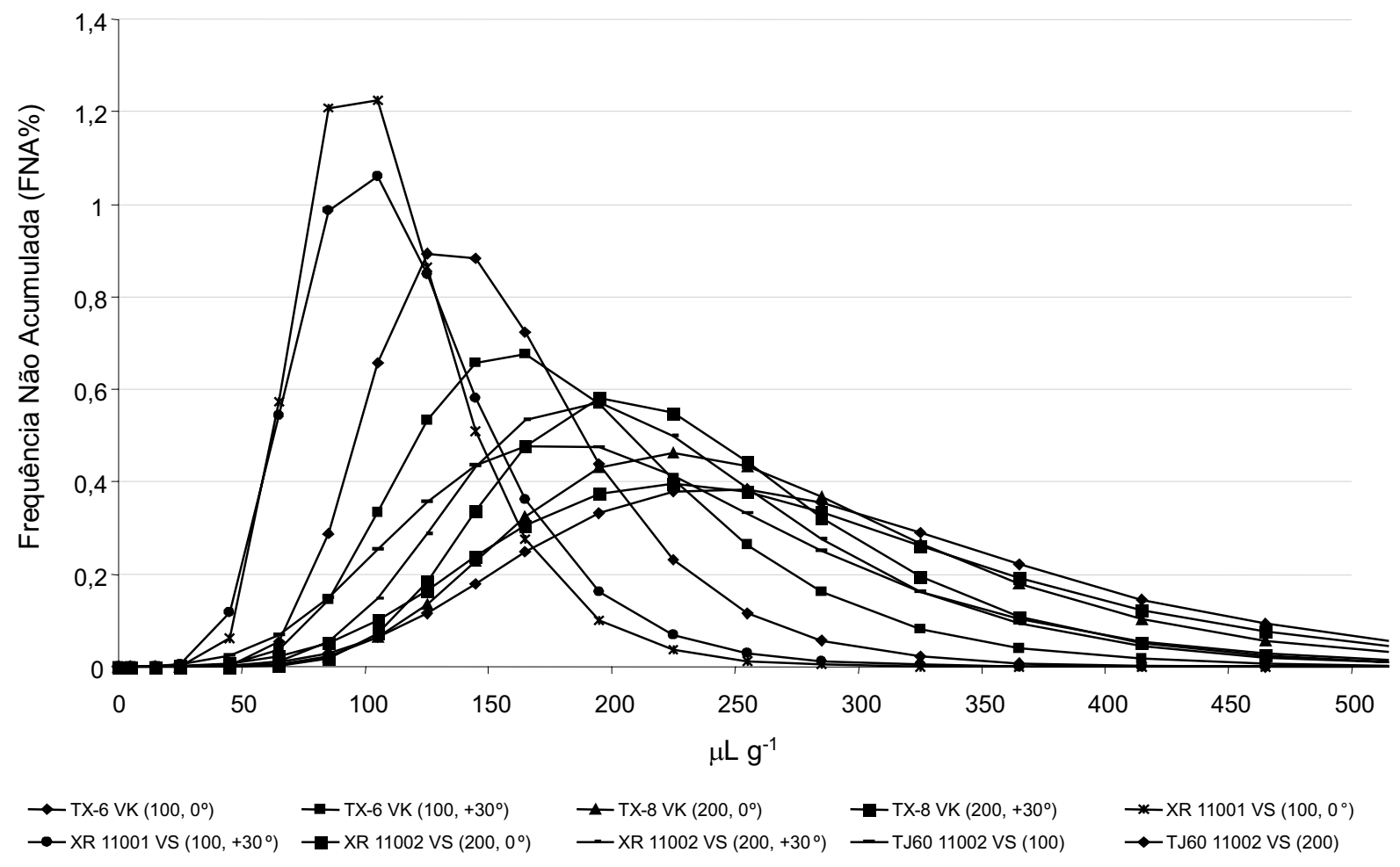

Figura 2 - Frequências não acumuladas em função da deposição do traçador em plantas de Commelina benghalensis, para diferentes volumes, ângulos e pontas de pulverização. 
Tabela 3 - Deposição da calda de pulverização, em $\mu \mathrm{L}$ de calda $\mathrm{g}^{-1}$ de massa seca, nas populações de plantas de Commelina benghalensis em que menos ocorreram depósitos para diferentes volumes, ângulos e pontas de pulverização

\begin{tabular}{|c|c|c|c|c|c|c|c|c|c|c|}
\hline \multirow{5}{*}{$\begin{array}{c}\text { Porcentagem } \\
\qquad(\%)\end{array}$} & \multicolumn{2}{|c|}{ TX-VK 6} & \multicolumn{2}{|c|}{ TX-VK 8} & \multicolumn{2}{|c|}{ XR $11001 \mathrm{VS}$} & \multicolumn{2}{|c|}{ XR 11002 VS } & \multicolumn{2}{|c|}{ TJ60 $11002 \mathrm{VS}$} \\
\hline & \multicolumn{10}{|c|}{ Ângulo } \\
\hline & $0^{\circ}$ & $+30^{\circ}$ & $0^{\circ}$ & $+30^{\circ}$ & $0^{\circ}$ & $+30^{\circ}$ & $0^{\circ}$ & $+30^{\circ}$ & -- & -- \\
\hline & \multicolumn{10}{|c|}{ Volume $\left(\mathrm{L} \mathrm{ha}^{-1}\right)$} \\
\hline & 100 & 100 & 200 & 200 & 100 & 100 & 200 & 200 & 100 & 200 \\
\hline 1 & 72,52 & 76,21 & 102,68 & 105,27 & 51,59 & 46,31 & 83,96 & 90,05 & 61,96 & 97,22 \\
\hline 5 & 89,79 & 99,45 & 136,81 & 132,32 & 63,80 & 60,98 & 123,78 & 117,62 & 94,53 & 138,17 \\
\hline 10 & 100,36 & 113,67 & 157,70 & 148,87 & 71,28 & 69,96 & 148,15 & 134,49 & 114,47 & 163,24 \\
\hline
\end{tabular}

Os percentis (1, 5 e 10\%) da população de plantas em que menos ocorreram depósitos da calda de pulverização podem ser responsáveis pelo insucesso da aplicação de produtos fitossanitários (Negrisoli et al., 2002). Assim, a ponta e/ou volume de aplicação que proporcionar maiores depósitos nas populações de plantas que apresentam maior dificuldade em interceptar as gotas pulverizadas poderão ser considerados os mais eficientes no processo de aplicação de produtos fitossanitários.

As plantas pulverizadas com os maiores volumes também receberam os maiores depósitos nos 1, 5 e 10\% das plantas em que ocorreram menos depósitos (Tabela 3).

Considerando a deposição nas plantas de C. benghalensis, a ponta TX-VK 8, no volume de $200 \mathrm{~L} \mathrm{ha}^{-1}$, apresentou os maiores valores de depósitos nos 1, 5 e 10\% das plantas que menos receberam depósitos, nos dois ângulos de aplicação. Ressalta-se que a utilização do ângulo de $+30^{\circ}$ proporcionou acréscimo nos depósitos apenas para as plantas que foram pulverizadas com a ponta TX-VK 6 no volume de $100 \mathrm{~L} \mathrm{ha}^{-1}$ nos 5 e $10 \%$ da população de plantas em que menos ocorreram depósitos de calda de pulverização.

Observou-se que todas as plantas apresentaram deposição das gotas de pulverização; o menor valor obtido foi de $46,31 \mu \mathrm{L}$ de calda $\mathrm{g}^{-1}$ de massa seca. $\mathrm{O}$ fato de todas as plantas apresentarem depósitos das gotas de pulverização ocorreu provavelmente devido ao menor acúmulo de ceras epicuticulares nas superficies foliares das plantas de $C$. benghalensis, como foi constatado por Rocha et al. (2007). Os diferentes padrões de cera sobre a epiderme determinam os diferentes graus de molhabilidade da superficie das folhas. Dessa maneira, as superficies cerosas resistem mais a pulverizações do que cutículas com superficies lisas (Procópio et al., 2003).

A ponta XR 11001 VS no volume de $100 \mathrm{~L} \mathrm{ha}^{-1}$, independentemente da angulação no momento da pulverização, foi a que proporcionou os menores depósitos, considerando a porcentagem de plantas dentro da população amostrada (1, 5 e $10 \%$ ) em que menos ocorreram depósitos de calda de pulverização; entretanto, foi a ponta que proporcionou a melhor uniformidade de distribuição das gotas.

De maneira geral, a utilização dos maiores volumes de aplicação proporcionou os maiores depósitos médios e pontuais. Da mesma forma, a angulação $\left(+30^{\circ}\right)$ das pontas de pulverização pode incrementar os depósitos de calda de pulverização e a uniformidade de deposição, porém são dependentes do volume de aplicação e da ponta de pulverização.

\section{LITERATURA CITADA}

COSTA, N. V. et al. pH foliar e deposição de gotas de pulverização em plantas daninhas aquáticas: Brachiaria mutica, Brachiaria subquadripara e Panicum repens. Planta Daninha, v. 23, n. 2, p. 295-304, 2005

HOLLOWAY, P. J. Surface factors affecting the wetting of leaves. Pest. Sci., v. 1, n. 1, p. 56-63, 1970.

NEGRISOLI, E. et al. Depósitos unitários de calda de pulverização com e sem surfactante em plantas de Salvinia molesta. Planta Daninha, v. 20, p. 51-56, 2002. Edição Especial.

PALLADINI, L. A.; RAETANO, C. G.; VELINI, E. D Choice of tracers for the evaluation of spray deposits. Sci. Agric., v. 62, n. 5, p. 440-445, 2005. 
PROCÓPIO, S. O. et al. Anatomia foliar de plantas daninhas do Brasil. Viçosa, MG: Universidade Federal de Viçosa, 2003. v. 1.118 p.

ROCHA, D. C.; RODELLA, R. A.; MARTINS, D Caracterização morfológica de espécies de trapoeraba (Commelina spp.) utilizando a análise multivariada.

Planta Daninha, v. 25, n. 4, p. 671-678, 2007.

SALYANI, M.; WHITNEY, J. D. Evaluation of methodologies for field studies of spray deposition. Trans. Am. Soc. Agron. Eng., v. 31, n. 2, p. 390-395, 1988

SCRAMIN, S. et al. Avaliação de bicos de pulverização de agrotóxicos na cultura do algodão. Pesticidas: R. Ecotoxicol. Meio Amb., v. 12, p. 43-50, 2002.
SOUZA, R. T.; VELINI, E. D.; PALLADINI, L. A. Aspectos metodológicos para análise de depósitos de pulverizações pela determinação dos depósitos pontuais. Planta Daninha, v. 25, n. 1, p. $195-202,2007$.

STEDEN, C. Untersuchungen zum einfluâ der tropfengröâe auf die belagsbildung und die biologische wirksamkeit gegen Oidium tuckeri Berk. An reben. 1992 118 f. Dissertation (Inaugural Dissertation zur Erlangung des Doktorgrades Justus-Liebig-Universität Gieâen) - JustusLiebig-Universität, Gieâen, 1992.

VELINI, E. D. Estudos e desenvolvimento de métodos experimentais e amostrais adaptados à matologia. 1995 250 f. Tese (Doutorado em Agronomia/Produção Vegetal) Universidade Estadual Paulista, Jaboticabal, 1995. 